\title{
TINGKAT KECEMASAN IBU HAMIL TRIMESTER III DALAM MENGHADAPI PERSALINAN PERTAMA
}

\author{
Rostina Afrida Pohan \\ Sekolah Tinggi Ilmu Kesehatan Sakinah Husada Tanjungbalai \\ Email : pohanrose@gmail.com
}

\begin{abstract}
The first pregnancy for a woman is one of the crisis periods in her life, peace of mind is important in facing childbirth, because it is recommended not only to do physical exercises but also psychological exercises to deal with childbirth. The type of research used in this research is descriptive with a cross sectional approach. This design was carried out on a set of objects that were studied to reduce the level of anxiety of pregnant women facing the first delivery, with a total sample of 20 pregnant women. The data collected in this study were analyzed using tabulating. Of the 20 respondents studied, 2 people (10\%) experienced mild anxiety, 12 people (60\%) experienced moderate anxiety, and 5 people (25\%) experienced severe anxiety and only 1 person 5\% of respondents did not experience anxiety. The results of this study indicate the level of anxiety of pregnant women has been described in this study. In connection with this research, it is suggested to health workers and midwives who assist in childbirth to provide regular counseling to pregnant women about pregnancy and the delivery process.
\end{abstract}

Keywords: The anxiety level of primigravida pregnant women; Facing Labor

\begin{abstract}
ABSTRAK
Kehamilan pertama bagi seorang wanita merupakan salah satu periode krisis dalam kehidupannya, ketenangan jiwa penting dalam menghadapi persalinan, karena itu dianjurkan bukan hanya melakukan latihan-latihan fisik namun latihan kejiwaan juga penting untuk menghadapi persalinan. Jenis penelitian yang digunakan dalam penelitian ini deskriptif dengan pendekatan cross secsional. Desain ini dilakukan terhadap sekumpulan objek yang diteliti terhadap penurunan tingkat kecemasan ibun hamil menghadapi persalinan pertama, dengan jumlah sampel sebanyak 20 orang ibu hamil. Data yang dikumpulkan dalam penelitian ini dianalisis dengan menggunakan tabulating. Dari 20 responden yang di teliti sebanyak 2 orang (10\%) mengalami kecemasan ringan, 12 orang $(600 \%)$ mengalami kecemasan sedang, dan 5 orang (25\%) mengalami kecemasan berat dan hanya 1 orang $5 \%$ responden yang tidak mengalami kecemasan.Hasil penelitian ini menunjukkan tingkat kecemasan ibu hamil telah diuraikan dalam penelitian ini. Sehubungan dengan penelitian ini disarankan kepada petugas kesehatan dan bidan yang menolong persalinan agar memberikan penyuluhan secara rutin kepada ibu-ibu hamil tentang kehamilan dan proses persalinan.

Kata kunci:Tingkat kecemasan ibu hamil primigravida; Menghadapi Persalina
\end{abstract}

\section{PENDAHULUAN}

\section{Latar Belakang (Opsional)}

Kehamilan pertama bagi seorang wanita merupakan salah satu periode krisis dalam kehidupannya. Pengalaman baru ini memberikan perasaan yang bercampur baur,antara bahagia dan penuh harapan dengan kekhawatiran tentang apa yang akan dialaminya semasa kehamilan (WHO 2009).

Kecemasan tersebut dapat muncul karena masa panjang saat menanti kelahiran penuh dengan ketidakpastian, selain itu bayangan tentang hal-hal yang menakutkan saat proses persalinan walaupun perubahan drastis, bukan hanya fisik tetapi juga psikologis (Kartono,1992).
Di Indonesia terdapat 373.000.000 orang ibu hamil yang mengalami kecemasan dalam menghadapi persalinan ada sebanyak 107.000 .000 orang $(28,7 \%)$. Sedangkan seluruh populasi di pulau Sumatra terdapat 679.765 ibu hamil yang mengalami kecemasan dalam menghadapi persalinan 355.873 orang $(52,3 \%)$ (Kemenkes RI, 2015).

Dengan makin tuanya kehamilan trimester III maka, perhatian dan pikiran Ibu hamil mulai tertuju pada sesuatu yang dianggap klimaks, sehingga kegelisahan dan ketakutan yang dialami Ibu hamil akan semakin intensif saat menjelang persalinan. Rasa takut menjelang persalinan menduduki peringkat teratas yang paling sering dialami Ibu selama hamil (Lestaringsih,2016). 
Tingkat kecemasan sangat berpengaruh terhadap kesejahteraan ibu hamil maupun janin yang didalam kandungan. Tingkat kecemasan yang rendah pada ibu hamil dapat mengurangi komplikasi yang ditimbulkan sehingga secara tidak langsung dapat mengurangi Angka kematian ibu (AKI) dan Angka Kematian Bayi (AKB) di Indonesia, sedangkan tingkat kecemasan yang tinggi dapat memperberat komplikasi yang terjadi dan meningkatkan AKI dan AKB hal ini sesuai dengan penelitian yang dilakukan oleh Trisniani (2016) dengan sampel 45 responden ibu hamil yang mengalami tingkat kecemasan sedang sebesar 52,7\% sedangkan yang mengalami tingkat kecemasan tinggi sebesar $57,8 \%$.

Berdasarkan hasil study pendahuluan di Puskesmas Datuk BandarKota Tanjungbalai ibu hamil sampai bulan Juni 2021yang melakukan pemeriksaan Ante Natal care berjumlah 63 orang dan hanya 20 orang saja dari ibu hamil yang primigravida trimester III, dari 20 orang primigravida mengaku merasa cemas saat-saat menjelang persalinan, pada umumnya Ibu-ibu merasa khawatir tidak mampu menghadapi proses persalinan.

\section{Tujuan Penelitian (Opsional)}

Tujuan dari penelitian ini adalah Mengidentifikasi tingkat kecemasan Ibu hamil dalam menghadapi persalinan pertama.

\section{METODE}

Penelitian ini merupakan penelitian deskriptif analitik dengan pendekatan cross sectional untuk mengidentifikasi tingkat kecemasan ibu hamil primigravida dalam menghadapi persalinan. Populasi dalam penelitian ini adalah ibu hamil Primigravida yang melakukan pemeriksaan ANC (Ante Natal care) mulai dari bulan Januari - Mei 2021 sebanyak 20 orang. Teknik pengambilan sampel menggunakan Accidental Sampling

Instument yang digunakan dalam penelitian ini menggunakan alat ukur kecemasan HRS-A (Hamilton Ratig Scale For Anxiety), yang terdiri dari 14 pertanyaan dengan teknik wawancara. Tehnik analisa data yang dipergunakan dan penelitian ini menggunakan perhitungan statistik sederhana yaitu presentase atau proporsi univariate. Dalam analisis univariat ini antara lain identifikasi responden berdasarkan umur, pendidikan, pekerjaan, paritas dan tingkat kecemasan.

\section{HASIL}

Data yang dikumpulkan adalah hasil dari penelitian yang dilakukan terhadap ibu-ibu primigravida di Puskesmas Datuk Bandar Kota Tanjungbalai. Pengumpulan data dilakukan dengan wawancara langsung terhadap responden menggunakan kuisioner. Berikut ini hasil penelitian nya

Tabel 1. Karakteristik Responden Berdasarkan Umur

\begin{tabular}{cccc}
\hline No & Umur & Jumlah & $\begin{array}{c}\text { Persentase } \\
\%\end{array}$ \\
1 & $<20$ tahun & 2 & $10 \%$ \\
2 & $20-35$ tahun & 18 & $90 \%$ \\
& Jumlah & 20 & $100 \%$ \\
\hline
\end{tabular}

Dari tabel diatas dapat dilihat bahwa dari 20 sampel yang diteliti terdapat 2 orang $(10 \%)$ yang memiliki umur dibawah 20 tahun, 18 orang (90\%) yang memiliki umur 20-35 tahun.

Tabel 2. Karakteristik Responden Berdasarkan Pendidikan

\begin{tabular}{cccc}
\hline No & Pendidikan & Jumlah & Persentase \\
1 & SD & 1 & 5 \\
2 & SMP & 4 & 20 \\
3 & SMA & 9 & 45 \\
4 & PT & 6 & 30 \\
& Jumlah & 20 & $100 \%$ \\
\hline
\end{tabular}

Dari tabel diatas dapat dilihat bahwa dari 20 sampel yang diteliti terdapat 1 orang $(5 \%)$ yang memiliki pendidikan SD, 4 orang $(20 \%)$ yang memiliki pendidikan SMP, 9 orang $(45 \%)$ yang memiliki pendidikan SMA, dan 6 orang $(30 \%)$ yang memiliki pendidikan perguruan tinggi.

Tabel 3. Karakteristik Responden Berdasarkan Pekerjaan

\begin{tabular}{llcc}
\hline No & Pekerjaan & Jumlah & Persentase \% \\
1 & Petani & 9 & 45 \\
2 & Wiraswasta & 4 & 20 \\
3 & PNS & 3 & 15 \\
4 & IRT & 4 & 20 \\
& Jumlah & & $100 \%$ \\
\hline
\end{tabular}

Dari tabel diatas dapat dilihat dari 20 sampel yang diteliti terdapat 9 orang $(45 \%)$ yang memiliki pekerjaan sebagai petani, 4 orang $(20 \%)$ yang memiliki pekerjaan sebagai wiraswasta, 3 orang $(15 \%)$ yang memiliki pekerjaan sebagai PNS, 4 orang (20\%) yang memiliki pekerjaan sebagai Ibu Rumah tangga 
Tabel 4. Karakteristik Responden Berdasarkan Sumber Informasi

\begin{tabular}{clcc}
\hline No & $\begin{array}{l}\text { Sumber } \\
\text { informasi }\end{array}$ & Jumlah & Persentase \% \\
1 & $\begin{array}{l}\text { Media } \\
\text { elektronik }\end{array}$ & 10 & 50 \\
2 & $\begin{array}{l}\text { Petugas } \\
\text { kesehatan } \\
\text { Total }\end{array}$ & 10 & 50 \\
\hline
\end{tabular}

Dari tabel diatas dapat dilihat bahwa dari 20 orang sampel yang diteliti terdapat 10 orang (50\%) yang memperoleh informasi dari media elektronik, 10 orang $(50 \%)$ yang memperoleh informasi dari petugas kesehatan.

Tabel 5. Tingkat Kecemasan Ibu Hamil Trimester III Menghadapi Persalinan Pertama

\begin{tabular}{llcc}
\hline No & \multicolumn{1}{c}{ Kecemasan } & Jumlah & $\begin{array}{c}\text { Persentase } \\
\%\end{array}$ \\
$\mathbf{1}$ & Tidak ada kecemasan & 1 & 5 \\
$\mathbf{2}$ & Kecemasan ringan & 2 & 10 \\
$\mathbf{3}$ & Kecemasan sedang & 12 & 60 \\
$\mathbf{4}$ & Kecemasan berat & 5 & 25 \\
$\mathbf{5}$ & Kecemasan panik & - & - \\
& Jumlah & 20 & $100 \%$ \\
\hline
\end{tabular}

Dari tabel diatas dapat dilihat bahwa dari 20 sampel yang diteliti terdapat 1 orang responden yang tidak memiliki kecemasan, 12 orang (65\%) yang di kategorikan ke dalam kecemasan ringan , 5 orang (25\%) yang di kategorikan kedalam kecemasan sedang, 2 orang (10\%) yang di kategorikan kedalam kecemasan berat dan tidak ada responden yang dikategorikan ke dalam kecemasan panik.

\section{PEMBAHASAN}

Hasil penelitian ini menunjukan bahwa dari 20 responden yang di teliti sebanyak 12 orang $(60 \%)$ mengalami kecemasan ringan, 5 orang (25\%) mengalami kecemasan sedang, dan 2 orang (10\%) mengalami kecemasan berat dan hanya 1 orang $5 \%$ responden yang tidak mengalami kecemasan.

Hal ini diasumsikan penulis penyebab terjadinya kecemasan karena kurangnya pengetahuan ibu hamil tentang proses persalinan, selain itu bayangan belum tentu terjadi sehingga timbul perasaan cemas dan takut.

Sesuai dengan teori yang menyebabkan cemas adalah pengaruh pengeluran adrenalin, hal ini akan mengakibatkan penyempitan pembuluh darah dan di pengaruhi kurang nya perhatian keluarga saat persalinan, sehinggga memperpanjang waktu persalinan maka resiko pada saat persalinan juga semakin banyak
Kecemasan itu berasal dari ketidak tahuan terhadap sesuatu hal yang baru Yang dapat menyebab kan seseorang menjadi khawatir gelisah. Oleh sebab itu untuk menurunkan kecemasan tersebut perlu di berikan penjelasan atau informasi kesehatan tentang hal yang baru atau pengalaman baru yang dialami oleh ibu hamil.

Mayoritas responden mengalami kecemasan pada gejala pertama yaitu cemas, firasat buruk, takut akan pikiran sendiri dan mudah tersinggung. Hal ini di sebabkan oleh pengalaman baru yang membuat reponden merasa ketakutan dan cemas karna kurang nya pengetahuan responden tentang proses tersebut.

Kecemasan berasal dari ketidak tahuan terhadap sesuatu hal baru yang dapat menyebabkan seseorang menjadi khawatir dan gelisah. oleh sebab itu di berikan perlakuan kepada responden yaitu pendidikan kesehatan dengan tujuan untuk memberikan penjelasan kepada responden tentang kehamilan, proses persalinan agar reponden tidak lagi mersa khawatir dan terus takut akan pikiran nya sendiri sehingga perempuan kecemasan responden. Kecemasan adalah ketegangan,rasa tidak aman dan kekhawatiran yang timbul karena dirasakan terjadi sesuatu yang tidak menyenangkan tetapi sumbernya tidak di ketahui dan berasal dari dalam

\section{KESIMPULAN}

Berdasarkan hasil penelitian ini dapat disimpulkan bahwa tingkat kecemasan pada ibu hamil primigravida trimester III di Puskesmas Semula Jadi yang terbanyak ialah kecemasan sedang, diikuti kecemasan berat dan kecemasan ringan. Sebagian kecil ibu hamil tidak mengalamikecemasan.

Terjadinya kecemasan dapat disebabkan oleh usia, tingkat pendidikan, pekerjaan, dan Sumber Informasi

\section{DAFTAR PUSTAKA}

1. Husna D. Perbedaan tingkat kecemasan dalam menghadapi persalinan pada ibu hamil nullipara dan multipara trimester III. Universitas Airlangga Surabaya; 2013. [Cited 2021 Jan 12] Available from:http://Journal.Unair.Ac.Id/DownloadFullpa pers-Msj6d80497333full.Pdf

2. Hawari, Dadan, Manajemen Stress, Cemas dan Depresi. Jakarta :BalaiPenerbit Fakultas Kedokteran Universitas Indonesia, 2011

3. Kurki, T, dkk. Depression and Anxiety in early Pregnancy and Risk For Preeclampsia. Journal Obstetrics and Gynecology. Volume 95, 2000

4. Dewi, dkk, Asuhan Kehamilan Untuk Kebidanan. Jakarta: Salemba medika, 2011

5. Shodiqoh, E.R., Fahriani, S. Perbedaan Tingkat Kecemasan Dalam Menghadapi Persalinan 
Antara Primigravida Dan Multigravida. Jurnal Berkala Epidemiologi. 2(1), 2014

6. Palupi, Fitria. (2014). Perbedaan Tingkat Kecemasan Ibu Primigravida dengan Multigravida dalam Menghadapi Proses Persalinan Kala I di Rumah Bersalin Ngudi Saras Jaten Karanganyar. Jurnal KESMADASKA. 5(1). 1 Januari 2014.

7. Husen, K. (2016). Pengaruh Pemberian Konseling Individu Sebelum Melahirkan Terhadap Tingkat Kecemasan Pada Ibu Postpartum Terhadap Tingkat Kecemasan Pada Ibu Postparrtum. Jurnal Kedokteran Diponegoro 6(2). 628-691

8. Astria, Y. (2009). Hubungan Karakteristik Ibu Hamil Trimester III dengan Kecemasandalam Menghadapi Persalinan di Poliklinik Kebidanan dan Kandungan RSUP Fatmawati. Jurnal Kecemasan. $\quad 10 \quad$ (19). 38-48. http://perpus.fkik.uinjkt.ac.id. Diakses tanggal 19 Desember 2020

9. World Health Organization (WHO). (2014). Maternal Mortality. Geneva : Departementof Reproductive Health and Research WHO

10. Shodiqoh ER, Fahriani S. Perbedaan tingkat kecemasan dalam menghadapi persalinan antara primigravida dan multigravida.Fakultas Kesehatan Universitas Airlangga. Surabaya; 2014. [cited 2020Des 20]. Available from: http://download.portalgaruda.org/article.php?artic le $=306829 \& \mathrm{val}=1122 \&$ title $=$ Anxiety $\% 20 \mathrm{Level} \%$ 20Difference $\% 20$ Between $\% 20$ The $\% 20$ Face $\% 20$ Of\%20Labour\%20And\%20Multigravida\%20Pri migravida 